\title{
Revestimentos comestíveis aplicados na conservação pós- colheita de goiabas: revisão da literatura
}

\author{
Márcia Liliane Rippel Silveira, Carla Rosane Barboza Mendonça
}

https://doi.org/10.4322/mp.978-65-991393-5-2.c10

\section{Resumo}

A expansão do mercado consumidor de goiaba in natura está condicionada à qualidade das frutas e ao aumento de sua vida útil pós-colheita. Na condição de fruta climatérica, a goiaba é altamente perecível e sofre rápida maturação após a colheita, devido a sua intensa atividade metabólica, que acarreta em uma série de transformações nas suas características físicas e químicas, demandando inúmeros esforços na ampliação da vida útil desta fruta. O emprego de coberturas comestíveis na conservação de frutas, na condição pós-colheita, tem sido preconizado como uma tecnologia emergente e de grande potencial, principalmente para aplicações sobre frutas de origem tropical, como a goiaba. Diversos biopolímeros têm sido avaliados na formulação dessas coberturas e, nesta revisão, são apresentados alguns exemplos aplicados à goiaba. Entre as principais matérias-primas das coberturas comestíveis destacam-se a gelatina, a cera de carnaúba, a quitosana, a fécula de mandioca e o alginato, além de materiais alternativos como a carboximetilcelulose, goma de caju, zeína de milho e biomassa de microalga. As coberturas atuam, controlando a respiração, por constituírem uma barreira física para trocas gasosas e perda de vapor de água, além de modificarem a atmosfera e retardarem a senescência da fruta, ou ainda como uma barreira antimicrobiana ou antioxidante. Constatou-se que os diferentes materiais testados, aplicados isolados ou em combinação, apresentam vantagens e desvantagens na conservação da qualidade e extensão da vida útil das goiabas in natura, portanto, ainda não há uma formulação que satisfaça todas as condições ou que possa ser aplicada de forma universal.

Palavras-chave: biopolímeros, fruta in natura, qualidade, vida de prateleira.

\section{Introdução}

Com uma vasta extensão territorial, o Brasil produz cerca de 43 milhões de toneladas de frutas anuais, sendo o terceiro maior produtor mundial, superado em produção apenas pela China e Índia. A fruticultura brasileira concentra-se principalmente nas regiões Nordeste, Sudeste e Sul, onde as condições de clima são bem distintas, permitindo o cultivo de um número variado de plantas frutíferas, tanto as tropicais como as de clima temperado (VIEIRA et al., 2011). O Brasil destaca-se como um dos principais produtores de goiaba (Psidium guajava L.), estando entre os dez maiores produtores mundiais desta fruta (COSER et al., 2014).

Com características sensoriais bastante apreciadas pelo consumidor e popular devido à sua disponibilidade e preço acessível (NIMISHA et al., 2013), bem como com a 
dupla aptidão para o consumo in natura e o processamento (RODRIGUES et al., 2018), a goiaba está entre as frutas tropicais brasileiras que se destacam por sua importância econômica e nutricional (AMORIM et al., 2015; ARAÚJO et al., 2015). A goiaba é uma fruta climatérica, que é caracterizada pelo aumento da taxa respiratória e produção auto catalítica de etileno durante o seu processo de amadurecimento (COSTA et al., 2017; FORATO et al., 2015). Durante o período pós-colheita, a senescência da fruta é rápida e compromete seus atributos de qualidade físicos, sensoriais e nutricionais, podendo levar à perdas significativas (TAVARES; ALMEIDA; GOMES, 2018). Sua vida útil é relativamente curta após a colheita e isto dificulta, ou até mesmo impede, o produtor de enviar suas frutas a centros consumidores mais distantes (SOARES et al., 2011).

A expansão do mercado consumidor de goiaba in natura está condicionada à qualidade das frutas e ao aumento da vida útil na pós-colheita (CAMPOS et al., 2011; COELHO et al., 2017). Um dos maiores problemas enfrentados pelos produtores na comercialização da fruta fresca, tanto no mercado nacional como no internacional, é sua alta perecibilidade (AZZOLINI; JACOMINO; SPOTO, 2004). Por isso, a preservação da qualidade da goiaba após a colheita ainda é um dos grandes desafios da fruticultura brasileira (ONIAS et al., 2018). Como esse fenômeno limita o transporte e armazenamento por períodos prolongados, devido às perdas irreversíveis que ocorrem (COELHO et al., 2017), a goiaba necessita da adoção de práticas de conservação que reduzam a velocidade das mudanças fisiológicas pós-colheita, para minimizar as perdas e prolongar a sua vida útil, garantindo a qualidade das frutas ofertadas e ampliando o seu período de comercialização (CARVALHO et al., 2001).

Os métodos normalmente empregados para a conservação de frutas intactas na condição pós-colheita fazem uso, prioritariamente, de refrigeração associada ou não a embalagens com atmosferas controladas. As condições mais comuns, e de comprovada eficiência, têm por base procedimentos nos quais a temperatura é reduzida logo após a colheita e a cadeia do frio, a uma temperatura apropriada para cada produto, é mantida preferencialmente em ambiente com alta umidade relativa, até a comercialização final (BARBOSA-CÁNOVAS et al., 2003; COSTA; CLEMENTE, 2012).

Na prática, contudo, a manutenção e o controle efetivo da temperatura em todas as etapas da cadeia não são uma condição trivial, o que é observado mesmo em países considerados desenvolvidos, nos quais as infraestruturas para este fim são notadamente superiores às brasileiras (RODRIGUE; NOTTEBOOM, 2009).

Desta forma, uma tecnologia alternativa cada vez mais divulgada e avaliada como um procedimento viável para elevar o tempo de vida de frutas e hortaliças, inteiras ou minimamente processadas, é o emprego de coberturas comestíveis protetoras. Esses revestimentos não têm como objetivo substituir o uso dos materiais convencionais de embalagens ou mesmo eliminar definitivamente o emprego do frio, mas sim o de apresentar uma atuação funcional e coadjuvante, contribuindo para a preservação da textura e do valor nutricional, reduzindo as trocas gasosas superficiais e a perda ou ganho excessivo de água. Ao promover alterações na permeação e, por conseguinte, afetar a atmosfera interna, alguns autores consideram o efeito dessas coberturas similares aos conseguidos pelas embalagens com atmosfera modificada (PARK, 2005; TURHAN, 2010), essas coberturas têm sido indicadas, principalmente, para produtos com alta taxa de respiração (ASSIS; FORATO; BRITTO, 2008).

As coberturas comestíveis são aplicadas ou formadas diretamente sobre a superfície das frutas, configurando membranas delgadas, imperceptíveis a olho nu e com 
diversas características estruturais, que são dependentes da formulação da solução filmogênica precursora. Como essas coberturas passam a fazer parte do alimento a ser consumido, os materiais empregados em sua formação devem ser considerados como GRAS (Generally Recognized as Safe), ou seja, serem atóxicos e seguros para o uso em alimentos (FDA, 2013). Cabe ressaltar que essas coberturas têm sido erroneamente denominadas de 'biofilmes', termo este totalmente inapropriado a este tipo de material ou aplicação. Segundo Assis e Brito (2014), 'biofilme' é um termo já consolidado em biologia e em ciências hídricas, de uso específico para a designação de colônias de bactérias imobilizadas sobre uma superfície sólida. São estruturas vivas organizadas, embebidas em matrizes poliméricas e dinâmicas, ou seja, apresentam alterações, como crescimento ao longo do tempo.

Neste contexto, o objetivo desta revisão é apresentar, de forma geral, os principais efeitos da aplicação de diferentes revestimentos comestíveis sobre a qualidade e a vida útil pós-colheita de goiabas, destinadas ao consumo in natura.

\section{Goiaba (Psidium guajava L.)}

A goiabeira é uma árvore frutífera pertencente à família Myrtaceae, que é composta por 130 gêneros e 3 mil espécies, distribuídas em diversas partes do mundo (EMBRAPA, 2010). A goiaba é uma fruta nativa das Américas do Sul e Central, sendo bastante amplo seu local de origem, o que parece ser na região compreendida do México ao Brasil. A expansão da espécie ocorreu em praticamente todas as regiões tropicais e subtropicais do globo, em razão da sua fácil adaptação às diferentes condições ambientais (PEREIRA; KAVATI, 2011).

Atualmente, a goiabeira é amplamente cultivada em países como México, Índia, China, Paquistão, África do Sul e Brasil, onde o cultivo em escala comercial ocorre em todas as regiões do país (PEREIRA; NACHTIGAL, 2002). De acordo com as últimas estatísticas disponíveis para a produção brasileira de goiaba, em 2017, foram produzidas 460.515 toneladas em uma área de 20.206 hectares, as regiões Nordeste (214.478 t) e Sudeste (210.860 t) concentram a maior parte da produção, Pernambuco $(135.540$ t) e São Paulo (173.926 t) se destacam como os principais estados produtores e juntos respondem por, aproximadamente, $70 \%$ da produção nacional (IBGE, 2018). Sua colheita concentra-se no período de janeiro a abril, apresentando declínio ao longo do ano, embora, em algumas regiões, com as técnicas culturais adotadas (poda e irrigação) a produção de frutas de goiabeira ocorra durante praticamente todo o ano (DEL'ARCO; SYLOS, 2018).

A exploração comercial da goiabeira iniciou-se em fins da década de 1950, sob dois modelos de produção bastante distintos, ou seja, goiabas para mesa e goiabas para processamento industrial (PEREIRA; NACHTIGAL, 2002). Entre as cultivares de goiaba para mesa destacam-se as de polpa vermelha, Ogawa $\mathrm{N}^{0} 1, \mathrm{~N}^{0} 2$ e $\mathrm{N}^{0} 3$, Sassaoka e principalmente a Pedro Sato, que é na atualidade a cultivar de casca rugosa mais plantada no Estado de São Paulo para a produção de fruta fresca, além da Kumagai, de polpa branca, base de exportação da goiaba brasileira (PEREIRA; KAVATI, 2011). Além de poder ser consumida in natura, a goiaba é utilizada na indústria de processamento de sucos, néctares, polpas, sorvetes, geleias e compotas, bem como serve de ingrediente na preparação de iogurtes, gelatinas e, recentemente, de molho agridoce (guatchup) (RANA; SIDDIQUI; GOYAL, 2015; REIS et al., 2007). A cultivar Paluma, que pode atender tanto ao processamento quanto ao consumo na forma de fruta fresca, é a mais cultivada do país, devido à grande capacidade produtiva por área plantada, por sua melhor conservação pós-colheita (resistência ao manuseio e transporte), pelas boas características industriais, frutas com bom rendimento e altos teores de sólidos solúveis. Atualmente, cerca de $70 \%$ das 
goiabeiras cultivadas no Brasil, com o objetivo de produção de frutas para processamento industrial, são da cultivar Paluma (AMORIM et al., 2015; PEREIRA; KAVATI, 2011).

O comércio internacional da goiaba brasileira e de seus derivados têm pouca expressão se comparado à dimensão da exportação brasileira de outras frutas, como a banana, a laranja, a manga e o melão (EMBRAPA, 2010). Apenas 0,06\% do total produzido são exportados (CHOUDHURY et al., 2001), por isso o principal destino da goiaba é o mercado interno, que absorve quase que a totalidade da produção nacional, que vem aumentando em volumes nos últimos anos (IBGE, 2018). Um dos motivos a justificar esse baixo desempenho é a preferência do mercado externo pela goiaba de polpa branca, em contraposição com a tendência da produção brasileira de goiaba, praticamente direcionada à produção de frutas de polpa vermelha, para atender à preferência do consumidor brasileiro (EMBRAPA, 2010).

Além do destino da produção, as frutas das cultivares de goiabeira diferem em relação ao tamanho, formato e coloração da polpa (GONZAGA NETO, 2007). A fruta é uma baga, sendo globosa, ou ovoide, ou piriforme, com 4 a $10 \mathrm{~cm}$ de diâmetro e peso variando de 100 a $450 \mathrm{~g}$. A casca apresenta coloração de verde-clara a amarelobrilhante, e a polpa é carnuda, de espessura variável, podendo ser de cor branca, ou amarela, ou vermelha ou rosa. As sementes são de formato reniforme, duras, com tamanho de 2 a $3 \mathrm{~mm}$ e em número variável conforme o cultivar (EMBRAPA, 2010). Nas características físico-químicas, como conteúdo de sólidos solúveis (SS), valores de $\mathrm{pH}$, acidez titulável (AT) e a relação SS/AT, que estão relacionadas à qualidade da fruta e às exigências do mercado consumidor, também já foi relatada a existência de variação entre cultivares (CAVALINI et al., 2006; COSER et al., 2014; LIMA; ASSIS; GONZAGA NETO, 2002).

A goiaba destaca-se entre as frutas tropicais e subtropicais, não só pela excelente aceitação para o consumo in natura, devido ao seu agradável aroma e sabor peculiar, mas também pelas suas características nutricionais. Considerada uma das melhores fontes de vitamina C (ácido ascórbico) (ARAÚJO et al., 2015; CERQUEIRA et al., 2009; FREIRE et al., 2013), possui altos teores de açúcares, vitamina $A$ e vitaminas do complexo B, principalmente tiamina (B1), riboflavina (B2) e niacina (PEREIRA; NACHTIGAL, 2002; YAN et al., 2006) e teores significativos de minerais, como cálcio, fósforo, potássio, ferro, zinco e cobre, sendo também rica em fibras (FREIRE et al., 2012; LIMA; ASSIS; GONZAGA NETO, 2002). Apresenta ainda, compostos fenólicos, flavonoides, carotenoides, sobretudo licopeno, e antocianinas, as maiores classes de pigmentos cuja ação antioxidante é um importante atributo nutricional (ARAÚJO et al., 2015; DEL'ARCO; SYLOS, 2018; KUSKOSKI et al., 2006; NIMISHA et al., 2013). Seu consumo na forma de fruta fresca garante o aproveitamento de suas propriedades nutricionais, mas é limitado, principalmente, por seu curto tempo de vida útil, pois a goiaba exibe alta taxa de respiração e rápido amadurecimento que leva ao seu perecimento durante o armazenamento (HONG et al., 2012). Além disso, nas frutas frescas, esses compostos bioativos podem ter suas quantidades e concentrações alteradas de acordo com a variedade, o grau de maturação e as condições climáticas e de cultivo da fruta (ARAÚJO et al., 2015; DUZZIONI et al., 2010; MELO et al., 2008).

A alta perecibilidade da goiaba é o principal problema enfrentado pelos produtores na comercialização da fruta in natura (CERQUEIRA et al., 2009). Por ser uma fruta tropical climatérica, a goiaba pode ser colhida na maturidade fisiológica, entretanto sua vida útil é relativamente curta, o que pode dificultar sua disponibilidade pós-colheita (OLIVEIRA; CEREDA, 1999). Goiabas colhidas completamente maduras apresentam capacidade de conservação de um a dois dias (MANICA et al., 2000), o que inviabiliza 
a comercialização em mercados distantes. Porém, a antecipação da colheita é motivo de dúvidas em relação à qualidade final da fruta (AZZOLINI; JACOMINO; SPOTO, 2004).

Os sinais visíveis de amadurecimento são as transformações na coloração, textura, sabor e aroma, as quais tornam a fruta comestível. As reações de síntese de novos compostos metabólicos ocorrem juntamente com inúmeras reações catabólicas que levam à completa degradação da fruta (AZZOLINI; JACOMINO; SPOTO, 2004). A taxa respiratória das goiabas, assim como a taxa de produção de etileno, depende de diversos fatores como condições de armazenamento, especialmente a temperatura, fase de maturação em que foi feita a colheita, além do cultivar e fatores genéticos. Os principais aspectos depreciadores da qualidade pós-colheita de goiabas envolvem 0 rápido amolecimento das frutas, a perda de coloração verde e do brilho da casca, o murchamento e a elevada incidência de podridões (CAMPOS et al., 2011; CERQUEIRA et al., 2009). Essas reações também podem promover o aumento da sensibilidade das frutas a danos mecânicos e aumentar a suscetibilidade a doenças (AZZOLINI; JACOMINO; SPOTO, 2004).

A vida útil das goiabas é de 3 a 5 dias quando armazenadas em temperatura ambiente (CAMPOS et al., 2011; FORATO et al., 2015). Quando as frutas colhidas estão no ponto maturo, recomenda-se para o armazenamento um ambiente refrigerado, com temperatura de $10{ }^{\circ} \mathrm{C}$ e umidade relativa em torno de $85 \%$ a $95 \%$, nestas condições, a fruta pode ser conservada por até 21 dias. Como a goiaba é uma fruta sensível, o armazenamento não deve ocorrer em temperatura inferior a $10{ }^{\circ} \mathrm{C}$, pois pode ocasionar injúria pelo frio (chilling injury) com danos severos na forma de lesões na superfície da casca, escurecimento da polpa que também pode adquirir consistência coriácea, além de amadurecimento irregular. A suscetibilidade à lesão pelo frio também é um fator que limita o potencial para sua comercialização (COSTA et al., 2017; EMBRAPA, 2010; VISHWASRAO; ANANTHANARAYAN, 2016).

A goiaba necessita de adoção de práticas para reduzir a velocidade das mudanças fisiológicas pós-colheita e com isso, retardar os processos de senescência. $O$ aumento da vida útil da goiaba em temperatura ambiente é desejável, uma vez que a quase totalidade das frutas comercializadas no Brasil, tanto no atacado quanto no varejo, não estão submetidas à refrigeração. A melhor conservação nessas condições pode facilitar o transporte a longas distâncias, o armazenamento por longos períodos, além de ampliar o seu período de comercialização (BASSETTO; JACOMINO; PINHEIRO, 2005; CARVALHO et al., 2001; CERQUEIRA et al., 2009).

O incremento de consumo da goiaba como fruta fresca está condicionado à melhoria na qualidade das frutas. Desta forma, a aplicação de tecnologias de conservação póscolheita é prioridade para a cultura da goiaba (EMBRAPA, 2010).

Diversos tratamentos pós-colheita têm sido testados em goiabas, embora muitos sejam eficientes em retardar a maturação e em conservar a qualidade das frutas, alguns interferem em suas características sensoriais. Outros estendem a vida útil de forma economicamente inexpressiva, ou deixam resíduos químicos (BASSETO, 2002).

A utilização de revestimentos comestíveis, associada aos procedimentos pós-colheita, tem-se mostrado bastante eficiente em prolongar a vida comercial de frutas frescas. Esses retardam os processos de amadurecimento e senescência, reduzindo o apodrecimento sem provocar alterações significativas em seu aspecto, sabor e qualidade nutritiva (VISHWASRAO; ANANTHANARAYAN, 2016). 


\subsection{Revestimentos comestíveis em goiabas}

Apesar das vantagens econômicas e de saúde, há diversos problemas que impactam a produtividade e a qualidade das goiabas, como doenças e variações causadas por fatores ambientais, porém, além do aumento de produtividade e resistência a pragas, é necessário investimento na manutenção da qualidade das frutas (NIMISHA et al., 2013).

A conservação pós-colheita usualmente empregada está, na sua maioria, centrada na cadeia do frio. A refrigeração é uma das técnicas mais práticas e eficientes para retardar o amadurecimento da goiaba (EMBRAPA, 2010), porém vários métodos para conservação pós-colheita foram avaliados em goiabas frescas, incluindo o uso de radiação ionizante para impedir a proliferação de microrganismos (SILVA et al., 2011; SINGH; PAL, 2009); radiação gama associada à atmosfera modificada passiva (CAMPOS et al., 2011); tratamento por imersão em solução concentrada de cloreto de cálcio (WERNER et al., 2009) ou cloreto de cálcio associado com o ácido giberélico (LIMA; DURIGAN, 2003); resfriamento por ar forçado (SIQUEIRA et al., 2014); exposição a 1-metilciclopropeno (BASSETTO; JACOMINO; PINHEIRO, 2005; CERQUEIRA et al., 2009; SINGH; PAL, 2008a) e embalagens plásticas (SINGH; PAL, 2008b) ou atmosfera modificada (GRIGIO et al., 2011; SAHOO et al. 2015). Apesar da eficiência dessas tecnologias, algumas técnicas possuem alto custo de implantação e podem gerar alto impacto ambiental (LOPES et al., 2018).

Neste contexto, o desenvolvimento e a aplicação de revestimentos ou coberturas comestíveis a base de polímeros naturais surge como uma alternativa para a manutenção da qualidade pós-colheita das frutas, além de prolongar seu tempo de conservação (FRÁGUAS et al., 2018; RODRIGUES et al., 2018; VISHWASRAO; ANANTHANARAYAN, 2016). Além disso, o uso de revestimentos comestíveis é de grande relevância para possibilitar maior disponibilidade da fruta in natura ao consumidor, e na preservação de suas características nutricionais e sensoriais, devido à manutenção de propriedades físico-químicas, propiciando, assim, valor comercial ao produto (COSTA et al., 2017; SALGADO et al., 2015).

Os revestimentos comestíveis têm sido bastante estudados nos últimos anos, especialmente em frutas frescas, devido, principalmente às suas propriedades de barreira, com a função de proteção contra fatores ambientais. Esses revestimentos podem ser usados para inibir ou reduzir a perda de umidade, oxigênio, dióxido de carbono, aromas e lipídeos, para o ambiente, diminuindo a taxa de respiração e alterações de textura, retendo componentes voláteis, constituintes do odor e do sabor, melhorando a integridade estrutural e a aparência das frutas e promovendo proteção física contra injúrias (COSTA et al., 2017; RIBEIRO et al., 2005; SANTOS et al., 2018). Além disso, esses materiais podem atuar como carreadores de compostos antimicrobianos, antioxidantes, entre outros (COSTA et al., 2017; FAKHOURI; GROSSO, 2003).

A aplicação de revestimentos em frutas leva à formação de uma cobertura na sua superfície externa, tal fato é responsável pela redução da transferência de umidade (transpiração) e das trocas gasosas (respiração) da fruta. A perda de massa em frutas in natura ocorre devido à perda de água para o ambiente externo, causada por processos de transpiração e respiração. Essa perda está diretamente relacionada com a qualidade da fruta e representa um dos maiores problemas durante 0 armazenamento das goiabas, com implicações sobre a aparência (cor), sabor e textura (amolecimento, perda de frescor e suculência), tornando-as pouco atrativas 
para a comercialização e consumo (COELHO et al., 2017; GOMES FILHO et al., 2016; ONIAS et al., 2018). Os valores aceitáveis de perda de massa para goiabas em condições de consumo variam entre 10\% e 15\% (FAKHOURI; GROSSO, 2003; SOARES et al., 2011). Desta forma, as coberturas comestíveis são utilizadas visando controlar a perda de água e consequentemente, de massa das goiabas armazenadas. A aplicação de coberturas pode ser realizada de duas formas: por meio de imersão rápida da fruta em uma solução filmogênica (o alimento é então deixado em repouso até que a água evapore e a película se forme sobre a fruta) ou por meio de aspersão da solução sobre o alimento. Os revestimentos comestíveis não devem interferir na aparência natural da fruta, devem possuir boa aderência e não podem promover alterações no sabor ou odor original da fruta (ASSIS; BRITO, 2014; TAVARES; ALMEIDA; GOMES, 2018).

As matérias-primas empregadas na formação das coberturas e revestimentos comestíveis podem ter origem animal ou vegetal, ou formarem um composto com a combinação de ambas. Polissacarídeos, lipídios (ceras) e proteínas são as classes de materiais mais empregados e a escolha, depende fundamentalmente das características do produto a ser revestido e do principal objetivo almejado com 0 revestimento aplicado (ASSIS; BRITO, 2014).

Existe a tendência de classificar os materiais empregados nos revestimentos em duas amplas categorias: hidrofílicos e hidrofóbicos. Nos materiais hidrofílicos predominam os grupos amino $\left(\mathrm{NH}_{2}\right)$ ou hidroxila $(\mathrm{OH})$ e carboxila $(\mathrm{COOH})$ na estrutura, que favorecem o acúmulo e a reorganização de moléculas polares, principalmente da água. Os polissacarídeos, como a celulose, a quitina, a goma xantana, a goma guar, a pectina, o amido e os polissacarídeos polieletrólitos, como a carboximetilcelulose, a quitosana, e o alginato são alguns exemplos destes materiais, que normalmente apresentam boa solubilidade em meio aquoso, favorecendo uma melhor dispersão do soluto e uma formação mais homogênea do filme (ASSIS; FORATO; BRITTO, 2008; ASSIS; BRITO, 2014).

Os materiais hidrofóbicos possuem grupos alquilas $\left(\mathrm{CH}_{3}, \mathrm{CH}_{2}-\mathrm{CH}_{3}\right)$ e aromáticos, que são apolares. Na presença de água esses materiais se aglomeram e não interagem com as moléculas polares. Nessa categoria, encontram-se as proteínas hidrofóbicas, óleos e ácidos graxos, parafinas e álcoois de cadeia longa. Para esta classe de materiais, os solventes adequados devem ser mais apolares, como o álcool, a acetona e o hexano (ASSIS; BRITO, 2014).

As coberturas hidrofílicas, por terem afinidade com a água, preservam o aspecto hidratado, mantendo por mais tempo a superfície brilhante e por isso são mais indicadas para superfícies fatiadas e frutas com aspectos brilhantes. As formulações hidrofóbicas, por sua vez, são indicadas para o revestimento de frutas com alta taxa de transpiração, nas quais a degradação ocorre essencialmente por perda de água, levando a desidratação e alteração do aspecto superficial. Essas indicações, contudo, são bastante genéricas e demais aspectos físico-químicos das frutas a serem revestidas devem ser avaliados para que a seleção de uma formulação tenha um resultado satisfatório (ASSIS; BRITO, 2014).

Diversos revestimentos comestíveis para o aumento da vida útil de goiabas in natura vêm sendo testados, e os trabalhos na literatura indicam a eficiência destes revestimentos na conservação das frutas na condição pós-colheita. A Tabela 1 traz algumas aplicações, indicando os materiais empregados na formação da cobertura protetora em cultivares de goiaba, bem como as condições e o tempo de armazenamento das frutas quando revestidas. 
Tabela 1. Exemplos de alguns materiais empregados na formação da cobertura protetora, as condições avaliadas e o tempo de armazenamento da goiaba, segundo dados publicados na literatura.

\begin{tabular}{|c|c|c|c|c|}
\hline Cultivar & Cobertura & Condições & $\begin{array}{l}\text { Armazenamento } \\
\text { (dias) }\end{array}$ & Referência \\
\hline $\begin{array}{l}\text { Pedro } \\
\text { Sato }\end{array}$ & Cera de carnaúba & $\begin{array}{c}25 \pm 2{ }^{\circ} \mathrm{C} \\
75 \pm 5 \% \text { UR }\end{array}$ & 6 & JACOMINO et al. (2003) \\
\hline Paluma & Cera de carnaúba & $\begin{array}{c}10 \pm 1^{\circ} \mathrm{C} \\
85 \pm 5 \% \text { UR } \\
27 \pm 2^{\circ} \mathrm{C} \\
70 \pm 9 \% \text { UR }\end{array}$ & 12 & RIBEIRO et al. (2005) \\
\hline - & $\begin{array}{l}\text { Fécula de mandioca/ } \\
\text { gelatina/emulsão lipídica }\end{array}$ & $25^{\circ} \mathrm{C}$ & 7 & COSTA et al. (2017) \\
\hline $\begin{array}{l}\text { Media } \\
\text { China }\end{array}$ & Cera de candelila & $\begin{array}{l}7^{\circ} \mathrm{C} \text { e } 10^{\circ} \mathrm{C} \\
80-85 \% \text { UR }\end{array}$ & 21 & $\begin{array}{l}\text { SALINAS-HERNÁNDEZ et } \\
\text { al. (2010). }\end{array}$ \\
\hline $\begin{array}{l}\text { Media } \\
\text { China }\end{array}$ & $\begin{array}{l}\text { Goma xantana/cera de } \\
\text { Candeuba }\end{array}$ & $\begin{array}{c}10{ }^{\circ} \mathrm{C} \text { e } 25^{\circ} \mathrm{C} \\
85 \% \text { UR }\end{array}$ & 34 & $\begin{array}{l}\text { ZAMBRANO- } \\
\text { ZARAGOZA et al. (2013) }\end{array}$ \\
\hline Kumagai & $\begin{array}{l}\text { Gelatina/triacetina/ácido } \\
\text { láurico }\end{array}$ & $\begin{array}{l}12^{\circ} \mathrm{C}, 42- \\
80 \% \text { UR }\end{array}$ & 20 & $\begin{array}{l}\text { FAKHOURI; GROSSO } \\
\text { (2003) }\end{array}$ \\
\hline Pérola & Quitosana & $\begin{array}{l}11^{\circ} \mathrm{C}, 90- \\
95 \% \text { UR }\end{array}$ & 12 & HONG et al. (2012) \\
\hline $\begin{array}{l}\text { Pedro } \\
\text { Sato }\end{array}$ & Quitosana/gelatina & $\begin{array}{c}5^{\circ} \mathrm{C} \text { e } 10^{\circ} \mathrm{C} \\
80 \pm 5 \% \text { UR }\end{array}$ & 28 & $\begin{array}{l}\text { OSHIRO; DRESCH; } \\
\text { SCALON (2012) }\end{array}$ \\
\hline $\begin{array}{l}\text { Pedro } \\
\text { Sato }\end{array}$ & Quitosana & $\begin{array}{l}27 \pm 1{ }^{\circ} \mathrm{C} \\
53 \pm 1 \% \text { UR }\end{array}$ & 8 & FRÁGUAS et al. (2018) \\
\hline Kumagai & $\begin{array}{l}\text { Quitosana/soro de } \\
\text { leite/glúten }\end{array}$ & $\begin{array}{c}22 \pm 2{ }^{\circ} \mathrm{C} \\
70 \pm 5 \% \text { UR }\end{array}$ & 8 & CERQUEIRA et al. (2011) \\
\hline Paluma & $\begin{array}{l}\text { Amido de semente de } \\
\text { jaca/quitosana/alginato de } \\
\text { sódio }\end{array}$ & $\begin{array}{c}10 \pm 2{ }^{\circ} \mathrm{C} \\
80 \pm 2 \% \text { UR } \\
25 \pm 3^{\circ} \mathrm{C} \\
75 \pm 4 \% \text { UR }\end{array}$ & 26 & RODRIGUES et al. (2018) \\
\hline $\begin{array}{l}\text { Pedro } \\
\text { Sato }\end{array}$ & $\begin{array}{l}\text { Fécula de } \\
\text { mandioca/quitosana }\end{array}$ & $\begin{array}{l}22 \pm 2{ }^{\circ} \mathrm{C} \\
62 \pm 6 \% \text { UR }\end{array}$ & 12 & SOARES et al. (2011) \\
\hline $\begin{array}{l}\text { Pedro } \\
\text { Sato }\end{array}$ & $\begin{array}{l}\text { Fécula de } \\
\text { mandioca/extratos }\end{array}$ & $\begin{array}{c}25^{\circ} \mathrm{C}, 65 \% \\
\text { UR }\end{array}$ & 9 & $\begin{array}{l}\text { GOMES FILHO et al. } \\
(2016)\end{array}$ \\
\hline $\begin{array}{l}\text { Pedro } \\
\text { Sato }\end{array}$ & $\begin{array}{l}\text { Fécula de mandioca/óleo } \\
\text { essencial de cravo-da- } \\
\text { índia }\end{array}$ & $\begin{array}{l}25^{\circ} \mathrm{C}, 80- \\
85 \% \text { UR }\end{array}$ & 10 & COELHO et al. (2017) \\
\hline $\begin{array}{l}\text { Pedro } \\
\text { Sato }\end{array}$ & $\begin{array}{l}\text { Fécula de mandioca/caseíné } \\
\text { extrato vegetal de barbatimã }\end{array}$ & $25 \pm 3^{\circ} \mathrm{C}$ & 12 & LOPES et al. ( 2018) \\
\hline- & $\begin{array}{l}\text { O-carboximetilquitosana } \\
\text { /óleo essencial de }\end{array}$ & $8^{\circ} \mathrm{C}$ & 17 & $\begin{array}{l}\text { TAVARES; ALMEIDA; } \\
\text { GOMES (2018) }\end{array}$ \\
\hline Paluma & Goma de cajueiro & $\begin{array}{c}10 \pm 2{ }^{\circ} \mathrm{C}, \text { UR } \\
90 \pm 5 \%\end{array}$ & 28 & BASTOS et al. (2018) \\
\hline Kumagai & $\begin{array}{l}\text { Goma de caju/ } \\
\text { carboximetilcelulose }\end{array}$ & $\begin{array}{c}25-28^{\circ} \mathrm{C} \\
76,0 \pm 12,4 \% \text { UR }\end{array}$ & $\hat{12}$ & FORATO et al. (2015) \\
\hline $\begin{array}{l}\text { Pedro } \\
\text { Sato }\end{array}$ & $\begin{array}{l}\text { Fécula de } \\
\text { mandioca/alginato de } \\
\text { sódio }\end{array}$ & $\begin{array}{c}10{ }^{\circ} \mathrm{C}, 70 \% \\
\text { UR }\end{array}$ & 25 & FONSECA et al. (2016) \\
\hline Lalit & $\begin{array}{l}\text { Hidroxipropilmetilcelulose/ } \\
\text { óleo de palma }\end{array}$ & $\begin{array}{l}24 \pm 1{ }^{\circ} \mathrm{C} \\
65 \pm 5 \% \text { UR }\end{array}$ & 12 & $\begin{array}{l}\text { VISHWASRAO; } \\
\text { ANANTHANARAYAN } \\
(2016)\end{array}$ \\
\hline Paluma & Zeína & $\begin{array}{c}23 \pm 2{ }^{\circ} \mathrm{C} \\
85 \pm 3 \% \text { UR }\end{array}$ & 12 & SANTOS et al. (2018) \\
\hline Paluma & $\begin{array}{l}\text { Biomassa de Spirulina } \\
\text { platensis }\end{array}$ & $\begin{array}{c}10 \pm 2{ }^{\circ} \mathrm{C} \\
85 \pm 5 \% \text { UR }\end{array}$ & 12 & ONIAS et al. (2018) \\
\hline
\end{tabular}


(-) Não informado.

As ceras podem ser incorporadas às operações de pós-colheita de goiabas, além de proporcionarem melhor aparência, devido ao aspecto lustroso, a cera pode aumentar o tempo de conservação por modificar a composição gasosa no interior da goiaba, diminuir a perda de água e retardar o amadurecimento. No entanto, é necessário identificar o tipo de cera mais adequado a cada cultivar (EMBRAPA, 2010). A película de cera aplicada na superfície do produto vegetal apresenta diferentes taxas de permeabilidade ao $\mathrm{O}_{2}, \mathrm{CO}_{2}$ e ao vapor de água em função das propriedades da matéria prima, de sua concentração e da espessura da película. A combinação adequada destes fatores é variável para cada fruta, conforme suas características fisiológicas (JACOMINO et al., 2003).

A cera à base de carnaúba vem sendo testada em frutas e hortaliças. Obtida a partir de uma palmeira brasileira, tem sido comercializada sob inúmeras marcas, em diferentes concentrações e misturas. Pode ser aplicada em produtos dos quais também se consome a casca, devido ao fato de não ser tóxica, ainda, confere brilho e reduz a perda de matéria fresca dos produtos, além de ser facilmente removível com água, se necessário (JACOMINO et al., 2003).

Jacomino et al. (2003) avaliaram os efeitos da aplicação de ceras comerciais à base de carnaúba na conservação pós-colheita de goiabas 'Pedro Sato' sob condição ambiente, durante seis dias. De acordo com os seus resultados, as ceras exerceram pouca influência nos teores de sólidos solúveis totais, acidez total titulável e ácido ascórbico, porém, foram eficientes em retardar o amadurecimento, reduzir a perda de massa e a incidência de podridões ao longo do armazenamento, além de conferir maior brilho as frutas. Ribeiro et al. (2005) também estudaram os efeitos de coberturas de cera de carnaúba Premium citrus ${ }^{\circledR}$ na conservação de goiabas 'Paluma', armazenadas sob refrigeração e em condição ambiente, pelo período de 12 dias. 0 uso da cera diminuiu a perda de massa e a degradação da clorofila na casca das frutas, contudo sua aplicação propiciou aumento de vida útil apenas para as frutas mantidas sob condição ambiente. Sob refrigeração, o uso da cera é dispensável para estender a vida útil da goiaba.

Costa et al. (2017) utilizaram como revestimento fécula de mandioca, gelatina e emulsão lipídica, composta por resina de colofônia e cera de carnaúba 15\%, e avaliaram os efeitos da aplicação sobre as características físico-químicas de goiabas de polpa vermelha armazenadas a temperatura ambiente. As coberturas à base de lipídio, seguidas do revestimento à base de fécula proporcionaram menor perda de massa, maior retenção da coloração verde, além de serem capazes de manter a firmeza da casca, em comparação com a amostra controle, mostrando-se eficientes para controlar o amadurecimento das goiabas e assim permitindo estender sua vida útil. O revestimento à base de gelatina não apresentou o mesmo efeito sobre a goiaba, pois a perda de massa foi próxima ao controle. Os autores sugerem que os revestimentos comestíveis à base de fécula e lipídeo são alternativas interessantes na conservação e aumento da vida útil das goiabas in natura e poderiam auxiliar na agregação de valor das frutas.

A influência da aplicação de uma camada de cera de candelila (Euphorbia anticyphilitica) em goiabas cultivar Media China, obtidas em dois estágios de maturação e mantidas durante três semanas à baixa temperatura de armazenamento $\left(7^{\circ} \mathrm{C}\right.$ e $\left.10^{\circ} \mathrm{C}\right)$ foi avaliada por Salinas-Hernández, Ulín-Montejo e Saucedo-Veloz (2010). Os resultados indicaram que a qualidade das frutas foi mantida por duas semanas. Os melhores resultados foram obtidos em frutas colhidas em estádio verdemaduro e mantidas a $10^{\circ} \mathrm{C}$, e frutas colhidas em estádio maduro armazenadas a $7^{\circ} \mathrm{C}$. 
O revestimento de cera reduziu significativamente a perda de peso em frutas de ambos os estágios de maturação. O estágio de maturação na temperatura de colheita e armazenamento teve um efeito significativo na extensão da vida útil do armazenamento.

Zambrano-Zaragoza et al. (2013), estudaram o efeito de revestimento à base de goma xantana e nanopartículas lipídicas de cera de Candeuba $^{\circledR}$ (mistura de cera de carnaúba e cera de candelila) em goiabas 'Media China' e reportaram que o revestimento tem potencial para aplicação, pois formou uma camada homogênea na casca da fruta, regulando a transpiração e outros processos metabólicos das frutas, 0 que contribuiu para o aumento do tempo de armazenamento e preservou a qualidade, como a cor, peso e textura em 19 dias em relação as frutas controle.

Outra forma de recobrimento de frutas in natura pode ser realizada com revestimentos obtidos a partir de polímeros naturais que são comestíveis, atóxicos, biodegradáveis e aderentes à superfície. A gelatina é um polímero proteico de origem animal, obtida a partir do colágeno, sendo de baixo custo, tendo sido utilizada como barreira à permeabilidade de gases no recobrimento de frutas. Revestimentos comestíveis com gelatina podem reduzir a migração de oxigênio, umidade e óleo, e ainda, podem carrear agentes antioxidantes ou antimicrobianos (FAKHOURI; GROSSO, 2003).

Coberturas filmogênicas produzidas com gelatina, triacetina e ácido láurico e aplicadas sobre goiabas brancas 'Kumagai', estocadas sob refrigeração durante 20 dias, foram avaliadas por Fakhouri e Grosso (2003). As coberturas mostraram-se eficientes no controle do amadurecimento das goiabas, permitindo estender sua vida útil em relação às frutas in natura sem cobertura. Entre as coberturas, a mistura de gelatina e triacetina se mostrou mais eficaz na preservação das características físico-químicas, e ainda preservou o brilho, a cor e a aparência das frutas. A incorporação de brilho, devido à adição das coberturas, teve um efeito favorável na aparência das amostras. Coberturas contendo ácido láurico, apesar de apresentarem aspectos positivos, influenciaram o sabor típico das goiabas. Entretanto, a lavagem das goiabas antes da degustação se mostrou suficiente para remover a presença de sabor estranho nas frutas.

Outro biopolímero para ser utilizado como revestimento comestível é a quitosana, um amino-polissacarídeo obtido da desacetilação da quitina, sendo um dos polímeros naturais mais abundantes em organismos vivos, como crustáceos, insetos e fungos. É uma fibra animal, que tem sido comprovada como não tóxica e biodegradável, que apresenta uma variedade de propriedades físicas e biológicas que resultam em diferentes aplicações. Quando utilizada como revestimento, possui a habilidade de modificar a atmosfera ao redor do produto por formar gel semipermeável aos gases e ao vapor de água, diminuindo as perdas por desidratação das frutas e, ainda, atrasando o amadurecimento e o escurecimento enzimático dos mesmos. A quitosana também pode auxiliar no controle do aparecimento de doenças pós-colheita, pois interfere diretamente no crescimento de patógenos e ativa diversas respostas de defesa nos tecidos vegetais (CERQUEIRA et al., 2011; FRÁGUAS et al., 2018; JIANG; LI 2001). O efeito da quitosana sobre a atividade dos fungos deve-se a possíveis alterações nas funções da membrana, através de interações com a superfície eletronegativa da quitosana, levando a mudanças de permeabilidade, distúrbios metabólicos e morte da célula (SOARES et al., 2011).

Hong et al. (2012), estudaram o revestimento à base de quitosana em goiaba cultivar Pérola e concluíram que o revestimento combinado com a refrigeração, durante 12 dias de armazenamento, inibiu a maturação e preservou a qualidade das 
frutas, pois reduziu a perda de massa e firmeza, retardou mudanças nos teores de clorofila e sólidos solúveis e na perda de acidez titulável e vitamina $\mathrm{C}$, além de reduzir o estresse oxidativo. Entretanto, Oshiro, Dresch e Scalon (2012) não observaram efeitos para os revestimentos gelatina $3 \%$ e quitosana $1 \%$ e $3 \%$ na preservação póscolheita de goiabas 'Pedro Sato', armazenadas a $5^{\circ} \mathrm{C}$ e $10^{\circ} \mathrm{C}$ por 28 dias. De acordo com os resultados, esses revestimentos não foram eficientes em retardar 0 amadurecimento e prolongar a preservação e qualidade das frutas nas temperaturas avaliadas. A baixa eficiência da gelatina no revestimento da goiaba favoreceu 0 aumento da concentração de açúcares nos tecidos, prejudicando a conservação das frutas.

Fráguas et al. (2018) encontraram bons resultados na manutenção da qualidade de goiabas 'Pedro Sato' tratadas com filmes de quitosana de diferentes pesos moleculares, em concentrações de $0,5 \%$ e 1,5\%. Todos os tratamentos com quitosana foram eficazes na manutenção da qualidade pós-colheita das frutas quando comparados com o controle, estendendo sua vida útil por oito dias à temperatura ambiente. As propriedades filmogênicas e de barreira da quitosana foram comprovadas pela redução na taxa de perda de massa das frutas revestidas e também pela menor perda no teor de pectina, resultado em atividades menores das enzimas hidrolíticas pectina metilesterase e $\beta$-D-glucosidase, que contribuiu para a manutenção da integridade da parede celular da fruta e na firmeza da polpa.

A firmeza da goiaba é um dos principais atributos de qualidade e também um importante indicativo de vida útil. A retenção da firmeza em goiabas por revestimentos comestíveis pode estar relacionada ao bloqueio dos poros da superfície das frutas e diminuição da permeabilidade das cascas a gases, como o oxigênio e o etileno. A menor ação do etileno influencia na redução da atividade das enzimas pectinolíticas, que degradam a parede celular (COSTA et al., 2017; LOPES et al., 2018).

Cerqueira et al. (2011) avaliaram o efeito de recobrimentos proteicos (concentrado proteico de soro de leite-CPSL e glúten) e de quitosana na conservação de goiabas 'Kumagai' armazenadas em condição ambiente durante oito dias. As frutas revestidas com $6 \%$ de quitosana mostraram uma menor perda de massa, quando comparados com outras concentrações de quitosana, outros tratamentos e o controle. O tratamento com $6 \%$ de quitosana também interferiu na perda normal de firmeza decorrente do amadurecimento da fruta, provavelmente ocorreu devido à restrição excessiva de trocas gasosas entre os tecidos vegetal e o ambiente externo. Isto resultou em uma alteração no metabolismo, causando uma redução nos processos de degradação da parede celular e quebra de pectina, mantendo assim uma maior firmeza do tecido.

A quitosana é um biopolímero de alto potencial para ser utilizado como revestimento comestível por si só, ou associada a outros compostos, na conservação pós-colheita de goiabas (RODRIGUES et al., 2018; SOARES et al., 2011). A vantagem dos revestimentos compostos é a combinação das características positivas de cada componente (FAKHOURI; BATISTA; GROSSO, 2003).

A influência de recobrimentos à base de amido de sementes de jaca adicionado à quitosana e ao alginato de sódio na manutenção da qualidade de goiabas 'Paluma', no armazenamento refrigerado, seguido da transferência para a condição ambiente, para simular a comercialização, foi avaliada por Rodrigues et al. (2018). O uso do revestimento de amido de semente de jaca (2\%) associado a quitosana (2\%) e alginato (2\%) foi eficiente na redução da taxa respiratória das frutas mantidas em condição ambiente por 10 dias. O recobrimento de amido e quitosana retardou 0 amadurecimento das frutas, manteve a firmeza e a coloração com intenção de compra 
e aparência superiores ao limite de aceitação, durante o armazenamento refrigerado e também após a transferência para a condição ambiente.

Os revestimentos comestíveis, além de controlarem as atividades metabólicas das frutas, podem ser adicionados de ingredientes ativos que interagem com o produto, preservando a sua qualidade e segurança (SOARES et al., 2011). Os revestimentos incorporados de aditivos quando em contato com a superfície da fruta, liberam, de forma gradativa, o composto para a superfície do alimento, onde a maioria das reações químicas e microbiológicas ocorre. A incorporação de óleos essenciais à matriz polimérica torna-se uma alternativa no desenvolvimento de filmes ativos na proteção do alimento de interesse, proporcionando ação antimicrobiana e antioxidante (COELHO et al., 2017). A substituição dos fungicidas químicos tradicionais por substâncias antimicrobianas naturais é um fator favorável para a aceitação de produtos agrícolas no mercado internacional, devido à estrita regulamentação do uso de produtos químicos para a produção de alimentos (SOARES et al., 2011).

Soares et al. (2011) desenvolveram um revestimento à base de fécula de mandioca com 1,0\% e 1,5\% de quitosana e avaliaram sua eficiência na conservação de goiabas 'Pedro Sato'. O uso do revestimento foi eficiente para prolongar a vida útil da goiaba, mantendo a cor verde da casca e a cor rosa da polpa. As frutas revestidas com quitosana $(1,5 \%)$ apresentaram maior força de resistência, mantendo a firmeza da polpa durante todo o período de armazenamento. A maior resistência apresentada pelas frutas revestidas garante melhor resistência às lesões mecânicas durante os processos pós-colheita e, consequentemente, maior durabilidade. As goiabas revestidas com filmes à base de fécula, acrescidos de quitosana também apresentaram menor perda de massa, mantiveram o teor de sólidos solúveis e apresentaram menores contagens de fungos filamentosos e leveduras, quando comparadas as frutas do grupo controle, durante o armazenamento.

Resultados semelhantes foram obtidos por Gomes Filho et al. (2016), que estudaram o efeito de revestimento à base de fécula de mandioca associado a substâncias antifúngicas na conservação pós-colheita de goiabas 'Pedro Sato', armazenadas durante nove dias em temperatura ambiente. A cobertura das frutas com diferentes concentrações de fécula de mandioca (3\% e 5\%) associada aos extratos vegetais de cravo-da-índia (Syzygium aromaticum L.) e melão-de-são-caetano (Momordica charantia L.) mostraram-se efetivas para minimizar a perda de massa das frutas e eficientes no controle de patógenos ao funcionarem como barreiras à contaminação do tecido, além de mostrarem propriedades antifúngicas, durante todo o período de armazenamento. Coelho et al. (2017) também obtiveram resultados satisfatórios com o uso de revestimento filmogênico à base de fécula de mandioca associado ao óleo essencial de cravo-da-índia, sobre a qualidade e redução de perdas por antracnose em goiabas 'Pedro Sato'. A aplicação do revestimento permitiu a extensão da vida útil da goiaba de 7 para 10 dias após a colheita em condição ambiente, retardou a mudança da coloração das frutas e possibilitou o acúmulo de licopeno e de $\beta-$ caroteno. Além disso, o óleo de cravo-da-índia associado ao revestimento reduziu a ocorrência de antracnose, independentemente do aumento da vida útil das frutas.

Outro estudo com goiabas 'Pedro Sato' mostrou que a utilização de revestimentos comestíveis de fécula de mandioca e caseína, com a adição de extrato vegetal de barbatimão (Stryphnodendron adstringens) foram eficientes na conservação da firmeza e colorimetria das goiabas, evitando seu amarelecimento e clareamento. Os revestimentos de fécula e caseína reduziram a perda de massa das frutas, durante os 12 dias de armazenamento, porém o extrato de barbatimão associado a esses revestimentos não proporcionou mudanças significativas em relação à perda de massa (LOPES et al., 2018). 
O composto O-carboximetilquitosana (O-CMQTS) é um derivado da quitosana, que apresenta como característica especial sua solubilidade em água. A presença dos grupos $\mathrm{COOH}$ e $\mathrm{NH}_{2}$ na sua estrutura lhe confere uma característica anfótera e, consequentemente, uma maior capacidade de perturbação da membrana em condições ácidas, básicas e neutras, comparado à quitosana. Essas propriedades fazem com que a O-CMQTS venha sendo estudada ao longo dos anos, para emprego na indústria de alimentos (TAVARES; ALMEIDA; GOMES, 2018).

Ao estudarem o recobrimento de goiabas com coberturas comestíveis à base de $O$ carboximetilquitosana associada ao óleo essencial de orégano (Origanum vulgare), após 17 dias de armazenamento a $8{ }^{\circ} \mathrm{C}$, Tavares, Almeida e Gomes (2018) verificaram que a utilização da cobertura foi eficiente para controlar o amadurecimento das goiabas e permitiu estender sua vida útil em relação às goiabas sem o revestimento. $O$ recobrimento também contribuiu para a redução da perda de massa das frutas em até $81 \%$, reduziu o grau de maturação e melhorou o aspecto visual das frutas. Os resultados da análise microbiológica de contagem de bolores e leveduras demonstrou redução na velocidade de crescimento microbiano nas frutas revestidas, com destaque para a cobertura contendo óleo de orégano, quando comparado às frutas sem cobertura.

A aplicação de revestimentos comestíveis em frutas se destaca por elevar o tempo de conservação permitindo uma maior flexibilidade de manuseio e comercialização. Neste sentido, Bastos et al. (2018) avaliaram a influência do revestimento de goma de cajueiro modificada na vida útil de goiabas 'Paluma', acondicionadas sob refrigeração e em temperatura ambiente. A goma de cajueiro é um heteropolissacarídeo composto por uma cadeia principal de $\beta-d$ galactose 1-3 ligado como cadeias de galactose e glicose, e tem sido estudada por suas propriedades funcionais, incluindo baixa toxicidade, biodegradabilidade, biocompatibilidade e ainda capacidade de formar revestimento. De acordo com os seus resultados, os revestimentos apresentaram um efeito positivo na conservação das goiabas, principalmente os formulados com goma de cajueiro reticulada. Combinando o uso do revestimento e temperatura, pode-se constatar que as goiabas armazenadas sob refrigeração apresentaram melhores resultados em relação a redução da perda de massa das frutas e da coloração verde da casca. As frutas armazenadas sob temperatura de refrigeração conservaram-se por até 28 dias, enquanto em temperatura ambiente por até 12 dias.

Formulações à base de goma de caju e carboximetilcelulose foram avaliadas como revestimentos comestíveis em goiabas da cultivar Kumagai, armazenadas por 12 dias em condições ambientais (FORATO et al., 2015). Ambos os revestimentos minimizaram a perda de massa das frutas, devido a redução da perda de água, além disso, foram eficazes na redução da infestação por fungos na polpa, preservaram a firmeza e retardaram as mudanças na cor da casca das goiabas.

Fonseca et al. (2016) avaliaram índices de qualidade pós-colheita de goiabas 'Pedro Sato', revestidas com fécula de mandioca, alginato de sódio e carboximetilcelulose. Independentemente do tratamento aplicado, as goiabas alcançaram maiores teores de vitamina $C$ após o armazenamento prolongado de 22 dias. O uso de revestimentos à base de fécula e alginato foram eficientes em retardar o amadurecimento das frutas armazenadas por quatro dias sob refrigeração, seguidos de três dias em temperatura ambiente. As goiabas revestidas com fécula de mandioca apresentaram os maiores teores de licopeno e de $\beta$-caroteno nos períodos de armazenamento mais prolongados, podendo-se recomendar este revestimento comestível para 0 armazenamento dessa fruta, para que se obtenha maior retenção destes importantes atributos nutricionais. No entanto, a composição dos diferentes revestimentos não teve 
influência sobre a atividade enzimática degradadora de parede celular, de modo a reduzir o processo de amaciamento das frutas.

Vishwasrao e Ananthanarayan (2016) estudaram o efeito do revestimento composto de hidroxipropilmetilcelulose (HPMC) e óleo de palma no amadurecimento de goiabas 'Lalit', durante 0 armazenamento. As frutas revestidas apresentaram retardo significativo na perda de peso e firmeza e na mudança de cor. O revestimento também afetou a fisiologia da fruta, mostrando um aumento mais lento no total de açúcares redutores e no teor de ácido ascórbico e retardou as atividades enzimáticas da peroxidase e polifenoloxidase da fruta. O retardo na produção de etileno pelas frutas revestidas em comparação com a fruta controle sugere que o revestimento comestível exerceu uma barreira à troca gasosa. A qualidade geral das frutas foi mantida pelo recobrimento aplicado, estendendo a vida das frutas a até 12 dias, comparativamente com os 9 dias das frutas não revestidas. A produção retardada de etileno pode ser correlacionada com a senescência tardia e uma susceptibilidade reduzida à deterioração.

A celulose é o polissacarídeo mais abundante no planeta e seus derivados apresentam diferentes permeabilidades ao vapor de água e gases e são bons formadores de filmes. A hidroxipropilmetilcelulose (HPMC) é aprovada como aditivo alimentar com a finalidade de formador de filme, estabilizante, espessante e agente de suspensão, porém as más propriedades de barreira à umidade do HPMC podem ser melhoradas pela incorporação de compostos hidrofóbicos, como ácidos graxos, na matriz de celulose para desenvolver um filme composto. O óleo de palma é uma das gorduras vegetais saturadas que é comercialmente utilizada devido ao seu baixo custo e alta estabilidade oxidativas. A combinação destes materiais em um revestimento composto comestível pode ser eficaz no controle do processo de maturação de frutas climatéricas como a goiaba (VISHWASRAO; ANANTHANARAYAN, 2016).

Revestimentos comestíveis podem ser formulados a partir de uma variedade de macromoléculas e entre as proteínas, a zeína, que constitui cerca de $50 \%$ das proteínas do endosperma do milho e contém cerca de $2 / 3$ de aminoácidos hidrofóbicos, apresenta excelentes propriedades de formação de filmes e revestimentos, pois têm boa resistência à umidade e baixa permeabilidade a vapor de água, o que favorece seu uso como barreira para diminuir a perda de água por frutas. Além disso, tem boa barreira a gases, reduzindo as taxas de respiração. Santos et al. (2018) observaram que os revestimentos à base de zeína (reticulada ou não com ácido tânico) aplicados em goiabas 'Paluma' aumentaram a vida útil das frutas em 3-4 dias e retardaram o processo de amadurecimento, fazendo com que a plena maturação não tenha sido atingida ao final de sua vida útil. Portanto, os autores recomendam que esse revestimento seja usado durante o transporte e a comercialização da goiaba, evitando assim que a plena maturação seja atingida.

A Spirulina platensis é uma microalga que apresenta na sua composição, alta concentração de proteína, entre 60 e 70\%. Por esse motivo, é considerada apropriada para o desenvolvimento de filmes estruturais, para o recobrimento de frutas na fase de pós-colheita (ONIAS et al., 2018). Outro estudo com goiaba 'Paluma' avaliou diferentes concentrações da microalga Spirulina platensis (0\%, 1\%, 2\% e 3\%) como revestimento biodegradável na conservação pós-colheita sob armazenamento refrigerado e ambiente. Os resultados mostraram que os revestimentos a base da biomassa de $S$. platensis foram eficientes em retardar a perda fisiológica de massa das frutas em ambas as temperaturas de armazenamento, sendo o tratamento na concentração de $1 \%$ a $10 \pm 2{ }^{\circ} \mathrm{C}$ o mais eficiente, proporcionando as menores perdas de massa quando comparado ao controle. As soluções preparadas a partir da 
biomassa de Spirulina, e empregadas no recobrimento das frutas foram de fácil formulação, por conterem maior quantidade de proteínas com alta solubilidade em água, e outra parte hidrofóbica que auxilia na formação de uma grade micelar para a estruturação do biofilme, portanto, resultando em boa solubilidade em água, observada pelo bom desempenho em relação a interação de complexos gelatinosos (ONIAS et al., 2018).

\section{Considerações Finais}

A alta perecibilidade faz da goiaba um excelente modelo para estudo dos efeitos de diferentes revestimentos comestíveis sobre a qualidade e a vida útil pós-colheita das frutas destinadas ao consumo in natura.

O emprego de coberturas e revestimentos comestíveis protetores em goiabas, embora seja ainda um processo em desenvolvimento, tem apresentado, nas últimas décadas, resultados bastante significativos, como uma prática auxiliar na conservação póscolheita desta fruta, cujo tempo de vida útil é consideravelmente reduzido em função da sua elevada atividade metabólica e das condições às quais é submetida após a colheita.

Com base na literatura, foram apresentados exemplos de algumas aplicações, indicando a extensão do tempo de vida útil da fruta, nas diferentes condições avaliadas.

Entre as matérias-primas mais comumente utilizadas na formação das coberturas comestíveis sobre a goiaba, destacam-se a gelatina, a cera de carnaúba, a quitosana, a fécula de mandioca e o alginato, além de materiais alternativos como a carboximetilcelulose, goma de caju, zeína de milho e biomassa de microalga. Cada um desses materiais, isolados ou combinados, foi utilizado com o objetivo de controlar a respiração, agindo como uma barreira física para trocas gasosas e perda de vapor de água, modificando a atmosfera e retardando a senescência, ou ainda na formação de uma barreira antimicrobiana ou antioxidante.

O que se depreende de concreto a partir dos trabalhos publicados, é que não há uma formulação que satisfaça todas as condições ou que possa ser aplicada de forma universal. Isso por que as características de uma cobertura, para que responda de forma satisfatória como barreira, dependem não somente do material em si, mas igualmente do produto a ser revestido e das suas particularidades, como a cultivar, fase de maturação em que foi feita a colheita e das condições de conservação. Outro aspecto a ser observado é que a cobertura não prescinde do emprego do frio. $\mathrm{Na}$ maioria dos exemplos apresentados a presença do frio é imprescindível para uma plena conservação na condição apropriada ao consumo.

\section{Referências}

AMORIM, D. A. et al. Adubação nitrogenada e potássica em goiabeiras 'Paluma': I. Efeito na produtividade e na qualidade dos frutos para industrialização. Revista Brasileira de Fruticultura, v.37, n.1, p. 201-209, 2015. https://doi.org/10.1590/01002945-051/14.

ARAÚJO, H. M. et al. Chemical profile and antioxidant capacity verification of Psidium guajava (Myrtaceae) fruits at different stages of maturation. Excli Journal, v.14, p.1020-1030, 2015. https://doi.org/10.17179/excli2015-522. 
ASSIS, O. B. G. de; FORATO, L. A.; BRITTO, D. de. Revestimentos comestíveis protetores em frutos minimamente processados. Higiene Alimentar, v. 22, n. 160, p. 99-106, 2008.

ASSIS, O. B. G.; BRITTO, D. Revisão: coberturas comestíveis protetoras em frutas: fundamentos e aplicações. Brazilian Journal of Food Technology, v.17, n.2, p.8797, 2014. https://doi.org/10.1590/bjft.2014.019.

AZZOLINI, M.; JACOMINO, A. P.; SPOTO, M. H. F. Estádios de maturação e qualidade pós-colheita de goiabas 'Pedro Sato'. Revista Brasileira de Fruticultura, v.26, n.1, p.29-31, 2004. https://doi.org/10.1590/S0100-29452004000100009.

BARBOSA-CÁNOVAS, G. V. et al. Handling and preservation of fruits and vegetables by combined methods for rural areas. Roma: FAO, 2003. 99 p. (Technical Manual). Disponível em: <http://www.fao.org/3/y4358e/y4358e00.htm>. Acesso 28 dez. 2020.

BASSETTO, E.; JACOMINO, A. P.; PINHEIRO, A. L. Conservation of 'Pedro Sato' guavas under treatment with 1-methylcyclopropene. Pesquisa Agropecuária Brasileira, v.40, n.5, p.433-440, 2005.

BASTOS, M.S. R. et al. Revestimento de goma de cajueiro modificada na vida útil de goiabas. Comunicado Técnico 241. Embrapa, Fortaleza, junho de 2018.

CAMPOS, A. J. et al. Radiação gama e atmosfera modificada passiva na qualidade de goiabas 'Pedro Sato'. Revista Brasileira de Fruticultura, v.33, n. spe1, p.350-356, 2011. http://dx.doi.org/10.1590/S0100-29452011000500044.

CARVALHO, H.A. et al. Efeito da atmosfera modificada sobre componentes da parede celular da goiaba. Ciência e Agrotecnologia, v.25, n.3, p.605-615, 2001.

CAVALINI, F. C. et al. Maturity indexes for 'Kumagai' and 'Paluma' guavas. Revista Brasileira de Fruticultura, v.28, n.2, p.176-179, 2006. http://dx.doi.org/10.1590/S0100-29452006000200005.

CERQUEIRA, T. S. et al. Controle do amadurecimento de goiabas 'Kumagai' tratadas com 1-metilciclopropeno. Revista Brasileira de Fruticultura, v.31, n.3, p.687-692, 2009. http://dx.doi.org/10.1590/S0100-29452009000300010.

CERQUEIRA, T. S. et al. Recobrimento de goiabas com filmes proteicos e de quitosana. Bragantia, v. $70,216-221,2011$. http://dx.doi.org/10.1590/S000687052011000100028.

CHOUDHURY, M. M. et al. Goiaba: Pós- Colheita. In: Agronegócio da goiaba. p. 915. EMBRAPA Informação Tecnológica. 45p. Il,; (Frutas do Brasil, 19) 2001.

COELHO, C. C. S. et al. Aplicação de revestimento filmogênico à base de amido de mandioca e de óleo de cravo-da-índia na conservação pós-colheita de goiaba 'Pedro Sato'. Revista Engenharia na Agricultura, v.25, n.6, p.479-490, 2017. http://dx.doi.org/10.13083/reveng.v25i6.723.

COSER, S. M. et al. Diversidade genética de seleções de goiabeiras Cortibel. Revista Brasileira de Fruticultura, v.36, n.2, p.391-398, 2014. http://dx.doi.org/10.1590/01002945-085/13. 
COSTA, J. M. C.; CLEMENTE, E. Refrigeration and cold chain effect on fruit shelf life. In: RODRIGUES, S.; FERNANDES, F. A. N. (Ed.). Advances in fruit processing technologies. Boca Taton: CRC Press, 2012. p. 287-330. https://doi.org/10.1201/b12088.

COSTA, L. C. et al. Aplicação de diferentes revestimentos comestíveis na conservação pós-colheita de goiabas (Psidium guajava L.). Brazilian Journal of Food Research, v.8, n.2, p.16-31, 2017. https://doi.org/10.3895/rebrapa.v8n2.4666.

DEL'ARCO, A. P. L. T.; SYLOS, C. M. Effect of industrial processing for obtaining guava paste on the antioxidant compounds of guava (Psidium guajava L.) 'Paluma' cv. Revista Brasileira de Fruticultura, v.40, n.2, p.1-10, 2018. https://doi.org/10.1590/0100-29452018011.

DUZZIONI, A.G. et al. Determinação da atividade antioxidante e de constituintes bioativos em frutas cítricas. Alimentos e Nutrição, v.21, n.4, p. 643-649, 2010.

EMPRESA BRASILEIRA DE PESQUISA AGROPECUÁRIA-EMBRAPA - A cultura da goiaba [editores técnicos, Flávia Rabelo Barbosa e Mirtes Freitas Lima]. - $2^{a}$ edição revista e ampliada - Brasília, DF: Embrapa Informação Tecnológica, 2010. 180 p.: il. $16 \mathrm{~cm}$ - (Coleção Plantar, 66).

FAKHOURI, F. M.; BATISTA, J. A.; GROSSO, C.. Efeito de coberturas comestíveis aplicadas em goiabas in natura (Psidium guajava) I: Desenvolvimento e caracterização de filmes comestíveis de gelatina, triacetina e ácidos graxos. Brazilian Journal of Food Technology, v. 6, n.2, p.301-308, 2003.

FAKHOURI, F.M.; GROSSO, C.R.F. Efeito de coberturas comestíveis na vida útil de goiabas in natura (Psidium guajava L.) mantidas sob refrigeração. Brazilian Journal of Food Technology, v.6, n.2, p.203-211, 2003.

FONSECA, M. J. O. et al. Uso de revestimento comestível para extensão da vida útil da goiaba 'Pedro Sato'. Revista Engenharia na Agricultura, v.24, n.2, p.101-110, 2016. https://doi.org/10.13083/reveng.v24i2.651.

FOOD AND DRUG ADMINISTRATION-FAD. Generally recognized as safe (GRAS). Silver Spring. Disponível em: <http://www.fda.gov/Food/IngredientsPackagingLabeling/GRAS/>. Acesso em: 19 dez. 2018.

FORATO, L. A. et al. Effect of cashew gum-carboxymethylcellulose edible coatings in extending the shelf-life of fresh and cut guavas. Food Packaging and Shelf Life, v. 5, p. 68-74, 2015. https://doi.org/10.1016/j.fpsl.2015.06.001.

FRÁGUAS, R. M. et al. Storage of guavas cv. Pedro Sato coated with low molecular weight chitosans. Brazilian Journal of Food Technology, v.21, p.1-9, 2018. https://doi.org/10.1590/1981-6723.11217.

FREIRE, J. M. et al. Avaliação de compostos funcionais e atividade antioxidante em farinhas de polpa de goiabas. Revista Brasileira de Fruticultura, v.34, n.3, p.847852, 2012. https://doi.org/10.1590/S0100-29452012000300026. 
FREIRE, J. M. et al. Quantificação de compostos fenólicos e ácido ascórbico em frutos e polpas congeladas de acerola, caju, goiaba e morango. Ciência Rural, v.43, n.12, p.2291-2296, 2013. https://doi.org/10.1590/S0103-84782013005000132.

GOMES FILHO, A. et al. Qualidade pós-colheita de goiabas 'Pedro Sato' tratadas com diferentes concentrações de fécula de mandioca associadas a substâncias antifúngicas. Agri-Environmental Sciences, v.2, n.1, p.37-51, 2016. Disponível em: $<$ https://revista.unitins.br/index.php/agri-environmental-sciences/article/view/189>. Acesso 29 dez. 2020.

GONZAGA NETO, L. Produção de goiaba. Fortaleza: Instituto Frutal, 2007. 64 p.

GRIGIO, M. L. et al. Efeito da modificação atmosférica em goiabas var. Paluma na redução de danos mecânicos em pós-colheita. Revista Agro@mbiente On-line, v.5, n.1, p.57-65, 2011. Disponível em: <https://revista.ufrr.br/agroambiente/article/view/406>. Acesso em: 19 dez. 2018. doi: dx.doi.org/10.18227/1982-8470ragro.v5i1.406.

HONG, K. et al. Effects of chitosan coating on postharvest life and quality of guava (Psidium guajava L.) fruit during cold storage. Scientia Horticulturae, v.144, n.1, p.172-178, 2012. https://doi.org/10.1016/j.scienta.2012.07.002.

INSTITUTO BRASILEIRO DE GEOGRAFIA E ESTATÍSTICA-IBGE. Produção Agrícola Municipal. Informações sobre culturas permanentes. Produção e área plantada de goiaba, Brasil, 2017. Disponível em: <http://www.sidra.ibge.gov.br>. Acesso em: 20 dez. 2018.

JACOMINO, A. P. et al. Conservação de goiabas tratadas com emulsões de cera de carnaúba. Revista Brasileira de Fruticultura, v.25, n.3, p.401-405, 2003. http://dx.doi.org/10.1590/S0100-29452003000300010.

JIANG, Y.; LI, Y. Effects of chitosan coating on postharvest life and quality of longan fruit. Food Chemistry, v.73, n.2, p.139-143, 2001. https://doi.org/10.1016/S03088146(00)00246-6.

KUSKOSKI, E. M. et al. Frutos tropicais silvestres e polpas de frutas congeladas: atividade antioxidante, polifenóis e antocianinas. Ciência Rural, v.36, n.4, p.12831287, 2006. http://dx.doi.org/10.1590/S0103-84782006000400037.

LIMA, M. A. C.; ASSIS, J. S. de; GONZAGA NETO, L. Caracterização dos frutos de goiabeira e seleção de cultivares na Região do Submédio São Francisco. Revista $\begin{array}{llll}\text { Brasileira de Fruticultura, v.24, n.1, p.273-276, } 2002 . & \end{array}$ http://dx.doi.org/10.1590/S0100-29452002000100061.

LIMA, M. A.; DURIGAN, J. F.. Conservação pós-colheita de goiabas utilizando-se cálcio e ácido giberélico, associados a diferentes filmes plásticos. Revista Brasileira de Armazenamento, v.28, n.2, p. 31-40, 2003.

LOPES, A. R. et al. Conservação de goiabas com revestimentos comestíveis de amido e caseína com extrato de barbatimão. Revista Engenharia na Agricultura, v.26, n.4, p.295-305, 2018. http://dx.doi.org/10.13083/reveng.v26i4.928.

MANICA, I. et al. Fruticultura Tropical-Goiaba. Porto Alegre: Cinco Continentes, 2000. 373p. 
MELO, E. A. et al. Capacidade antioxidante de frutas. Revista Brasileira de Ciências Farmacêuticas, v.44, n.2, p.193-201, 2008. https://doi.org/10.1590/S151693322008000200005.

NIMISHA, S. et al. Molecular breeding to improve guava (Psidium guajava L.): Current status and future prospective. Scientia Horticulturae, v. 164, p. 578-588, 2013. https://doi.org/10.1016/j.scienta.2013.10.017.

OLIVEIRA, M.A.; CEREDA, M.P. Efeito da película de mandioca na conservação de goiabas. Brazilian Journal of Food Technology, v.2, p.97-102, 1999.

ONIAS, E. A. et al. Revestimento biodegradável à base de Spirulina platensis na conservação pós-colheita de goiaba Paluma mantidas sob diferentes temperaturas de armazenamento. Revista de Ciências Agrárias, v.41, n.3, p.849-860, 2018. http://dx.doi.org/10.19084/RCA17201.

OSHIRO, A. M.; DRESCH, D. M.; SCALON, S. P. Q. Preservação de goiabas 'Pedro Sato' armazenadas sob atmosfera modificada em refrigeração. Revista de Ciências Agrárias, v.35, n.1, p.213-221, $2012 . \quad$ Disponível em: <http://www.scielo.mec.pt/scielo.php?script=sci_arttext\&pid=S0871-

018X2012000100021>. Acesso 29 dez. 2020.

PARK, H. J. Edible coatings for fruits. In: JONGEN, W. W. F. (Ed.). Fruit and vegetable processing: improving quality. Boca Raton: CRC Press, 2005. p.331-345.

PEREIRA, F. M.; KAVATI, R. Contribuição da pesquisa científica brasileira no desenvolvimento de algumas frutíferas de clima subtropical. Revista Brasileira de Fruticultura, v.33, n.spe1, p.92-108, 2011. https://doi.org/10.1590/S010029452011000500013.

PEREIRA, F. M.; NACHTIGAL, J. C. Melhoramento da goiabeira. In: BRUCKER, C. H. (Ed.). Melhoramento de fruteiras tropicais. Viçosa: Editora UFV, 2002. p.267-289.

RANA, S.; SIDDIQUI, S; GOYAL, A.. Extension of the shelf life of guava by individual packaging with cling and shrink films. Journal of Food Science and Technology, v. 52, n.12, p.8148-8155, 2015. https://doi.org/10.1007/s13197-015-1881-5.

REIS, K. C. et al. Phisical-chemistry evaluate of guava osmostic dehidration in solutions different. Ciência e Agrotecnologia, v.31, n.3, p.781-785, 2007. https://doi.org/10.1590/S1413-70542007000300026.

RIBEIRO, V. G. et al. Armazenamento de goiabas 'Paluma' sob refrigeração e em condição ambiente, com e sem tratamento com cera de carnaúba. Revista Brasileira de Fruticultura, v.27, n.2, p.203-206, 2005. https://doi.org/10.1590/S010029452005000200005.

RODRIGUE, J.P.; NOTTEBOOM, T. The cold chain and its logistic. In: RODRIGUE, JP.; COMTOIS, C.; SLACK, B. The geography of transport systems. 2nd ed. New York: Routledge, 2009. 297 p.

RODRIGUES, A. A. M. et al. Physiology and postharvest conservation of 'Paluma' guava under coatings using Jack fruit seed-based starch. Revista Brasileira de Fruticultura, v.40, n.2, p. 1-8, 2018. https://doi.org/10.1590/0100-29452018352. 
SAHOO, N. R. et al. Comparative study of MAP and shrink wrap packaging techniques for shelf life extension of fresh guava. Scientia Horticulturae, v. 182, p. 1-7, 2015. https://doi.org/10.1016/j.scienta.2014.10.029.

SALGADO, P. R. et al. Edible films and coatings containing bioactives. Current $\begin{array}{lllll}\text { Opinion in Food } & \text { Science, } & \text { v.5, }\end{array}$ https://doi.org/10.1016/j.cofs.2015.09.004.

SALINAS-HERNÁNDEZ, R. M.; ULÍN-MONTEJO, F.; SAUCEDO-VELOZ, C. Effect of waxing and temperature of storage on the conservation of guava (Psidium guajava L.) cultivar 'Media China'. Acta Horticulturae, v.849, p. 401-408, 2010. https://doi.org/10.17660/ActaHortic.2010.849.49.

SANTOS, T. M. et al. Revestimento de goiabas com zeína. Comunicado Técnico 237. Embrapa, Fortaleza, abril de 2018. Disponível em:<https://ainfo.cnptia.embrapa.br/digital/bitstream/item/177626/1/COT18004.pdf>.

Acesso em: 19 dez. 2018.

SILVA, J. M. et al. Use of ionising radiation technology as a method of postharvest conservation of guava. International Journal of Postharvest Technology and Innovation, v. 2, p. 168-179, 2011. https://doi.org/10.1504/IJPTI.2011.041039.

SINGH, S. P.; PAL, R. K. Controlled atmosphere storage of guava (Psidium guajava L.) fruit. Postharvest Biology and Technology, v.47, p.296-306, 2008b. https://doi.org/10.1016/j.postharvbio.2007.08.009.

SINGH, S. P.; PAL, R. K. Ionizing radiation treatment to improve postharvest life and maintain quality of fresh guava fruit. Radiation Physics and Chemistry, v.78, p.135140, 2009. https://doi.org/10.1016/j.radphyschem.2008.09.007.

SINGH, S. P.; PAL, R. K. Response of climacteric-type guava (Psidium guajava L.) to postharvest treatment with 1-MCP. Postharvest Biology and Technology, v.47, p.307-314, 2008a. https://doi.org/10.1016/j.postharvbio.2007.08.010.

SIQUEIRA, A. M. A. et al. Vida útil pós-colheita de goiaba cv. 'Paluma' submetida ao resfriamento rápido por ar forçado. Revista Ciência Agronômica, v. 45, n. 1, p. 45-51, $2014 . \quad$ Disponível em: <http://ccarevista.ufc.br/seer/index.php/ccarevista/article/view/1514>. Acesso $29 \mathrm{dez}$. 2020.

SOARES, N. F. F. et al. Antimicrobial edible coating in post-harvest conservation of guava. Revista Brasileira de Fruticultura, v.33, n.spe1 p.281-289, 2011. https://doi.org/10.1590/S0100-29452011000500035.

TAVARES, L. R. ALMEIDA, P. P. de; GOMES, M. F. Avaliação físico-química e microbiológica de goiaba (Psidium guajava) revestida com cobertura comestível à base de $O$-carboximetilquitosana e óleo essencial de orégano (Origanum vulgare). $\begin{array}{lllll}\text { Multi-Science Journal, } & \text { v.1, } & \text { n.13, } & \end{array}$ https://doi.org/10.33837/msj.v1i13.590.

TURHAN, K. N. Is edible coating an alternative to MAP for fresh and minimally processed fruits? Acta Horticulturae, v.876, n.1, p.299-305, 2010. https://doi.org/10.17660/ActaHortic.2010.876.40. 
VIEIRA, L. M. et al. Fenólicos totais e capacidade antioxidante in vitro de polpas de frutos tropicais. Revista Brasileira de Fruticultura, v.33, n.3, p.888-897, 2011. http://dx.doi.org/10.1590/S0100-29452011005000099.

VISHWASRAO, C.; ANANTHANARAYAN, L. Postharvest shelf-life extension of pink guavas (Psidium guajava L.) using HPMC-based edible surface coatings. Journal of Food Science and Technology, v.53, n.4, p.1966-1974, 2016. http://dx.doi.org/10.1007/s13197-015-2164-x.

WERNER, E.T. et al. Efeito do cloreto de cálcio na pós-colheita de goiaba Cortibel. Bragantia, v.68, n.2, p.511-518, 2009. http://dx.doi.org/10.1590/S000687052009000200026.

YAN, L. Y. et al. Antioxidant properties of guava fruit: comparison with some local fruits. Sunway Academic Journal, v.3, p.9-20, 2006.

ZAMBRANO-ZARAGOZA, M. L. et al. Use of solid lipid nanoparticles (SLNs) in edible coatings to increase guava (Psidium guajava L.) shelf-life. Food Research $\begin{array}{llll}\text { International, } & \text { v.51, } & \text { n.2, } & \text { p.946-953, }\end{array}$ http://dx.doi.org/10.1016/j.foodres.2013.02.012.

\section{Autores}

Márcia Liliane Rippel Silveira ${ }^{1}$, Carla Rosane Barboza Mendonça ${ }^{2, *}$

1. Curso de Pós-graduação Lato Sensu em Ciência dos Alimentos, Centro de Ciências Químicas, Farmacêuticas e de Alimentos, Universidade Federal de Pelotas, Campus Universitário, Caixa Postal, 354, 96010-900, Pelotas, RS, Brasil.

2. Centro de Ciências Químicas, Farmacêuticas e de Alimentos, Universidade Federal de Pelotas, Campus Universitário, Caixa Postal, 354, 96010-900, Pelotas, RS, Brasil.

* Autor para correspondência: carlaufpel@hotmail.com 